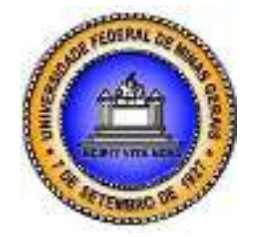

\title{
INOVAÇÃO SOCIAL EM UM EMPREENDIMENTO ECONÔMICO SOLIDÁRIO: ALTERNATIVAS PARA O ENFRENTAMENTO DA MARGINALIZAÇÃO
}

\section{SOCIAL INNOVATION IN A SUPPORTIVE ECONOMIC DEVELOPMENT: ALTERNATIVES TO COMBAT THE MARGINALIZATION}

\section{LA INNOVACIÓN SOCIAL EN UNA EMPRESA ECONÓMICA DE APOYO: ALTERNATIVAS PARA COMBATIR LA MARGINACIÓN}

\author{
Guipson Fontes Pinheiro Neto \\ Universidade Federal do Ceará \\ gpinhh@gmail.com
}

\author{
Mônica Cavalcanti Sá de Abreu \\ Universidade Federal do Ceará \\ mabreu@ufc.br
}

Submetido em: 23/01/2014

Artigo aceito em: 05/06/2014

\section{Resumo}

O artigo apresenta o processo de inovação social num empreendimento econômico solidário para enfrentar a marginalização de pacientes com distúrbios psiquiátricos. Este trabalho classifica-se como uma pesquisa qualitativa, do tipo exploratório e descritivo, tendo o estudo de caso como estratégia. Os dados da pesquisa foram analisados segundo a técnica de análise de conteúdo. Sob o olhar da inovação social, a Cooperativa Social do Centro de Atenção Psicossocial (COOPCAPS) representa ser a própria inovação, pois foi nova solução encontrada pelos indivíduos, com o apoio de distintas entidades da sociedade, motivados para o enfrentamento da situação de marginalização.

Palavras-chave: Inovação Social, Economia Solidária, Empreendimento Econômico Solidário, Desenvolvimento Sustentável

\begin{abstract}
This paper present the process of social innovation in a solidarity economic enterprise in order to help psychiatric patients. This research is classified as a qualitative, exploratory and descriptive, having the case study as a strategy. The research data was analyzed according to the content analysis technique. Under the vision point about social innovation, the COOPCAPS represents the innovation itself, because it was new solution found by individuals, with the support of distinct organizations of society, motivated to face the situation of marginalization. Keywords: Social Inovation. Solidarity Economy. Solidarity Economic Enterprise, Sustainable Development
\end{abstract}

\section{Resumén}

El artículo presenta el proceso de innovación social en una empresa económica de apoyo para hacer frente a la marginación de los pacientes con trastornos psiquiátricos. Este trabajo se ubica como una investigación cualitativa, exploratoria y descriptiva, y el estudio de caso como estrategia. Los datos de la encuesta fueron analizados según la técnica de análisis de contenido. Desde la perspectiva de la innovación social, la Cooperativa Social Centro de Atención Psicosocial (COOPCAPS) es ser la propia innovación, porque era nueva solución encontrada 



por los individuos, con el apoyo de diferentes entidades de la sociedad, motivados para hacer frente a la situación de marginación.

Palabras clave: Innovación Social, Economía Solidaria, Desarrollo de Alcance Económico, Desarrollo Sostenible

\section{Introdução}

Antigos modelos de pensar e agir vêm a ser colocados em xeque, numa realidade plural, diante de novas lógicas representadas pelo maior envolvimento de atores da sociedade para enfrentar ambientes de incertezas e agravamento de mazelas sociais. Assim, observa-se que os atores do âmbito público e privado, sentindo-se ameaçados, mobilizam-se em busca de possíveis soluções, a assumir posturas mais reflexivas, coletivas e sustentáveis, e, desse modo, conseguem inovar.

Espera-se que a inovação ocasione mudanças que atinjam a vertente econômica sem omitir a vertente social. Afinal, como já endossado por Boava e Macedo (2011), até mesmo antes do "empreender" - promessa -, encontra-se o homem enquanto ser doador de sentido ao mundo, que a partir de suas ações tenta modificar a realidade, num processo a fazer valer de inovação que não meramente sob uma única vertente.

$\mathrm{O}$ ato de inovar sempre existiu, ainda que num processo informal e baseado no empirismo (GOLLO, 2006; ZAWISLAK, 1995), visando à resolução de problemas. Contudo, a transformação social originada por inovação social - aqui discutida - refere-se algo que extrapola a resolução de problemas de ordem técnica ou simplista, comumente lembrados quando se fala em inovação.

Dentre as mazelas que se tem combatido com a inovação para uma transformação social, encontram-se o desemprego e a miséria, esses são constrangedores para aqueles que lutam pela implementação de uma "outra" economia. No Brasil foi popularmente nomeada como Economia Solidária, estabelecida sob parâmetros de cooperação e solidariedade, características que a diferenciaria da lógica antiga, mas ainda vigente e predominante.

O contexto de oposição de uma antiga lógica, a mobilização de atores a fim de inovar para solucionar problemas, a emergência de uma "outra" economia e seus empreendimentos que cooperam e são solidários, tudo isso vem a levantar alguns questionamentos e instigar a práticas de pesquisa. Diante do exposto e numa perspectiva local, assumiu-se como problema de pesquisa a seguinte indagação: de que maneira ocorre o processo de inovação social num empreendimento econômico solidário (EES), no estado do Ceará?

A realização desta pesquisa justificou-se pela necessidade de evidenciar o que de inovador vem a fundamentar a possível trajetória de empreendimentos da Economia Solidária e quais são as consequências para os seus participantes. Pois é plausível assumir que a inovação social e mudanças decorrentes não se restrinjam apenas a discursos, sendo relevante evidenciar experiências e a sua promoção.

Os próximos capítulos estruturantes deste artigo versam sobre inovação, inovação social, Economia Solidária e seus empreendimentos como temáticas para fundamentação teórica; percurso metodológico adotado; apresentação dos resultados; bem como as considerações finais e sugestões para próximas investigações. 

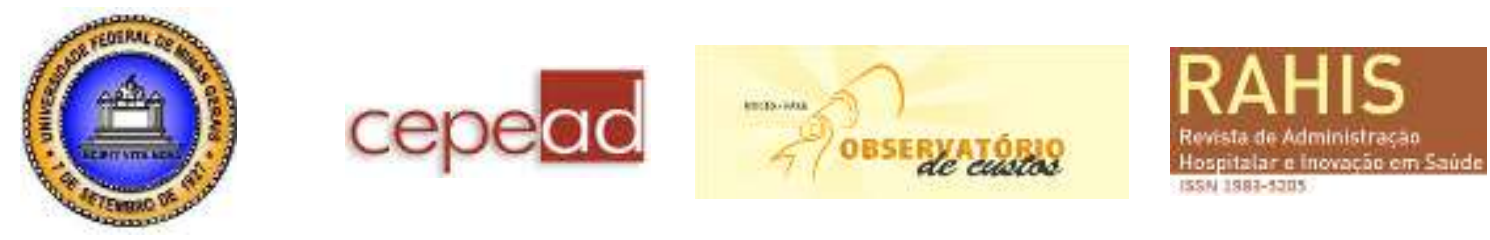

Referencial Teórico: Inovação: entendendo tipologias, conceitos e o seu caráter social

Inovação é um vocábulo antigo que é amplamente difundido e, em consequência a isso, assume muitos significados. No tocante às definições do que seria inovação, nota-se uma variedade de autores, os quais ressaltam: o pensamento criativo (SCHUMPETER, 1939), a percepção do novo (ROGERS; SHOEMAKER, 1971), o surgimento de novas técnicas (ROTHWELL; ZEGVELD, 1982), a introdução de mudanças, como também, do ferramental do empreendedor (DRUCKER, 2003), a complexidade aliada à interatividade (GOLLO, 2006) e, a exploração de novas ideias visando competitividade (OCDE, 2005).

Essas abordagens revelam a inovação sob diferentes pontos de vista, desde o econômico (SCHUMPETER, 1939), científico e tecnológico (ROTHWELL; ZEGVELD, 1982), ao empreendedor (DRUCKER, 2003), organizacional (GOLLO, 2006) e competitivo (OCDE, 2005). Todavia, tal diversidade desdobra-se na evidenciação do que seria um ambiente organizacional propício à inovação, além de um esperado desdobramento em tipologias de inovação. De acordo com Gollo (2006), ambientes (e.g. organizações, arranjos produtivos regiões e países) que conseguem desenvolver e difundir inovações, detém um diferencial para melhor lidar com mudanças e contingências de mercado, situando-se, dessa maneira, nas fronteiras do conhecimento.

Quanto à inovação, nota-se que o sentido do "novo" é transversal a suas variadas tipologias. Dentre os tipos de inovação vistos num levantamento bibliográfico, a inovação sistêmica (DRUCKER, 2003) chama atenção por imprimir o significado de mudança à inovação e remetê-la a especificação econômica e social. Não sendo difícil entender a inovação econômica como consequência da mudança deliberada, consciente do forte viés de mercado que perpassa os tipos de inovação. Todavia, Drucker (2003) sinaliza que a inovação não se restringe a inovação econômica, sobretudo, pode incidir em inovação social.

Posterior à sinalização de Drucker (2003), Maurer, Marquesan e Silva (2010) alegam que as inovações sociais não pretendem atender, exclusivamente, a uma lógica de competição de mercado, em contraste ao acentuado aspecto econômico ou tecnológico dos variados tipos de inovação. Mas sim, objetivam o atendimento de uma necessidade urgente: geração e manutenção de um bem-estar geral da sociedade e daqueles que se encontram marginalizados.

A inovação social, em sua definição, segundo Maurer, Marquesan e Silva (2010) e alguns pesquisadores do Centre de Recherche Sur les Innovations Sociales - CRISES (TARDIF, 2005; CLOUTIER, 2003; PETITCLERC, 2003; LÉVESQUE, 2002), remete-se a um termo de muitos significados, tendo por base 3 eixos complementares: o território, as condições de vida e, de trabalho e emprego.

Lévesque (2002) revela que se tem definido, no contexto das organizações, amplamente, a inovação social como novas formas de fazer as coisas, novas práticas sociais, novas combinações, novas abordagens, novos conceitos, tais como know-how e novas habilidades para responder aos problemas existentes. No campo das ciências administrativas e organizações, a inovação social refere-se às mudanças ocorridas nas relações dos indivíduos e do trabalho, sendo que o nível da mudança se daria no ambiente organizacional e levaria a impactos econômicos na sociedade, como observado por Maurer, Marquesan e Silva (2010).

Segundo Cloutier (2003), a inovação social é uma "nova resposta" a uma situação social considerada insatisfatória, situação que pode ocorrer em todos os setores da sociedade. Tal inovação atende a esse título porque visa o bem-estar dos indivíduos e comunidades, sendo definida na ação e numa mudança duradoura, nas quais as "maneiras de fazer as coisas" são 

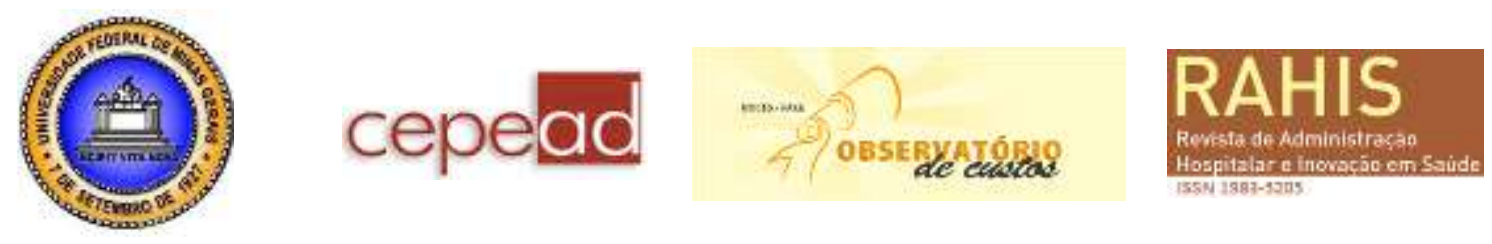

modificadas via a desconstrução de estruturas não-satisfatórias, para uma posterior reconstrução de estruturas de liberdade que propiciem ações deliberadas.

Cloutier (2003) constatou que, para a maioria dos investigadores, a inovação social é definida pelo seu caráter inovador e por proporcionar positivos efeitos sociais, sendo resultante da cooperação entre as diversas partes interessadas. Por requerer a participação dos usuários, em vários níveis, durante o processo de criação e de implementação da inovação, ela pode ser vista como um processo coletivo de aprendizagem e de criação do conhecimento.

A inovação social, a partir das considerações de Cloutier (2003), destina-se a atender a aspiração de ordem social. $\mathrm{O}$ que também veio a ser reforçado nos estudos proferidos por Maurer; Marquesan e Silva (2010), Tyszler (2007) e Tardif (2005) acerca da transformação e inovação social, a frisar que sua definição está intimamente relacionada a um contexto de transformações em torno do progresso social, econômico, político e cultural, sendo considerada o desenvolvimento de novas soluções para a resolução de problemas emergentes.

Tardif (2005), por exemplo, reconhece a existência de vários tipos de inovação, contudo, foca a inovação social sob o seu caráter múltiplo, reconhecendo também que ela tende, no longo prazo, a influenciar o modelo de desenvolvimento a ser adotado pelos atores sociais, quer seja por organizações, por territórios e por comunidades. Antes de Tardif (2005), Cloutier (2003) afirma que a inovação social pode ser definida a partir de grandes dimensões de análise, a saber: a) o próprio objeto, sua natureza, b) os setores da sociedade envolvidos, c) as mudanças de destino, d) o processo criativo e de execução, e e) resultados obtidos.

Contudo, Petitclerc (2003) frisa que a teoria da mudança social não pode ser reduzida a dualidade entre os atores e estruturas, e adverte que os atores sociais não são apenas produtores de inovação, eles podem também ser o produto da inovação. Para o autor, as interações sociais, organizações, instituições públicas e movimentos sociais se baseiam na lógica paradoxal da autonomia e dependência um com os outros, por isso cada nível do sistema social pode impor um ritmo à mudança social, de acordo com a sua lógica.

Lógica remetida por Tardif (2005) ao contexto de crise generalizada que se instala e que se acentuam em diferentes momentos, bem como nas exigências que resultam no pensar diferente, no reorientar de estratégias de mudanças para organizações e territórios, o que impacta no surgimento de uma nova ordem socioeconômica que toma forma. Em decorrência, o surgimento de inovações sociais sugere um conjunto de constrangimentos e oportunidades que encorajam a diversos atores redefinirem os seus sistemas de ação.

Tardif (2005) reforça que um conjunto de constrangimentos refere-se às mudanças e processos macroestruturais, às novas exigências do mercado por concorrência e competitividade, ao aumento do livre comércio e aos avanços tecnológicos, dentre outros. Segundo Petitclerc (2003), mais do que a capacidade dos atores de defender os seus interesses pessoais, é fato que, a capacidade de conviver com os outros, especialmente em redes e movimentos sociais, permitem-lhes se libertar dos antigos constrangimentos e adentrarem num processo de transformação social originado por inovações.

Inúmeros são os promotores da inovação social, cada um com os seus interesses, culturas, valores e identidades, que muitas vezes são orientadas de forma diferente durante o processo de inovação. Nesse processo, destaca-se que ações de consulta, participação, mobilização e coordenação de recursos internos e externos fazem-se presentes a proporcionar um aprendizado coletivo que auxiliam na superação dos obstáculos encontrados.

Observa-se que a discussão acerca da inovação social vem alinhada a discussão de uma "outra" economia, dita ora social (esfera internacional), ora solidária (esfera nacional). Santana 

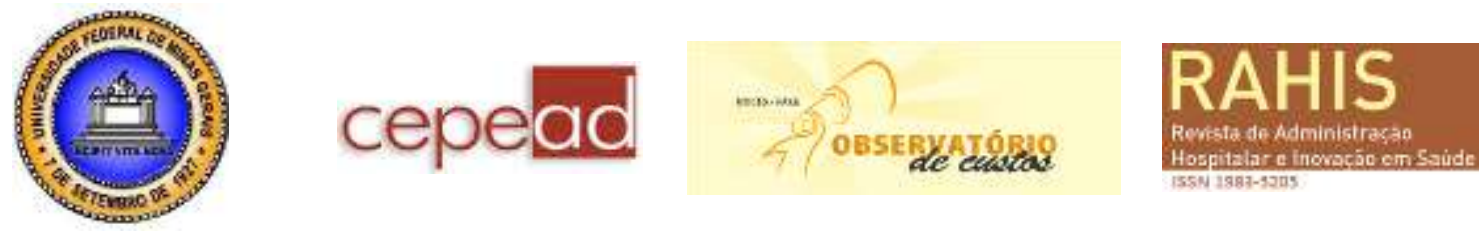

(2008) supõe que tamanha atenção voltada a essa economia, traduzi-se pela constante preocupação em se conhecer práticas de relações sociais e econômicas que, de alguma forma preferencialmente imediata - consigam estruturar alternativas para a minimização de problemas, possibilitando tanto a sobrevivência, quanto a melhoria da qualidade de vida para as mais variadas populações em todo o planeta.

\section{Percurso Metodológico}

No processo de planejamento da pesquisa fez-se necessário atentar para a classificação da pesquisa desenvolvida, concomitante ao delineamento de seu percurso metodológico. Ciente disso, esta pesquisa classifica-se como uma pesquisa qualitativa, do tipo exploratório e descritivo (GODOY, 2005; GIL, 2002; RICHARDSON, 1999).

Para sua devida realização, adotou-se o estudo de caso como estratégia, observando as ponderações de Godoy (2005) e Yin (2005). Yin (2005) reforça que essa estratégia é utilizada quando se busca compreender fenômenos sociais complexos e que a sua realização oportuniza uma investigação para se preservar as características mais significativas dos fatos. Por sua vez, Godoy $(2005$, p. 127) defende que a estratégia de pesquisa qualitativa referente aos estudos de caso pode trazer "importantes contribuições quando a intenção do pesquisador não é explorar casos típicos, mas examinar casos extremos ou pouco usuais".

A área de estudo selecionada para o alcance de dados contemplou os empreendimentos econômicos solidários (EES) do estado do Ceará, em particular, os oriundos de incubadoras tecnológicas de cooperativas populares (ITCPs). Diante à diversidade das atividades econômicas desempenhadas pelos empreendimentos de interesse desta pesquisa, foram selecionados EES dos segmentos de confecção e artesanato como alvo da pesquisa, pela representatividade deles no cenário nacional e nordestino (MTE, 2010).

A busca por empreendimentos econômicos solidários, tendo as ITCPs como referências, justificou-se pelo entendimento de que essas incubadoras são fontes viáveis para o alcance dos empreendimentos a serem pesquisados. Essa busca condisse com a pretensão dos pesquisadores - cientes de que o processo de incubação envolver a legalização das organizações incubadas (CANÇADO; CANÇADO, 2009; CANÇADO; VIEIRA; CANÇADO, 2009). -, em alcançar um conjunto de EES devidamente formalizados e que tivessem concluído o processo de incubação num período superior a 2 anos.

Além de ter incubadoras como fonte de referência para o delineamento dos empreendimentos-alvo da pesquisa, o período superior a 2 anos também foi ponderado, uma vez que esse prazo é considerado razoável para consolidação de empreendimentos e de suas atividades produtivas, se comparado com os prazos acerca da mortalidade das pequenas empresas no país (SEBRAE, 2007; RTS, 2005). De um conjunto de 35 empreendimentos informados pelas ITCPs consultadas, 7 EES inicialmente corresponderam ao segmento de interesse da pesquisa. No entanto, o alcance de todos esses não foi possível por 3 fatores: a) não concluíram o processo de incubação, b) não atenderam ao período de 2 anos ou c) não existem mais.

Neste artigo, o empreendimento - Cooperativa Social do Centro de Atenção Psicossocial (COOPCAPS) - foi selecionado para discussão, a partir dos resultados das entrevistas com três de seus sócio-cooperados. A definição da quantidade de sujeitos da pesquisa esteve associada diretamente aos critérios de julgamento dos pesquisadores, sendo dessa maneira flexível, a 

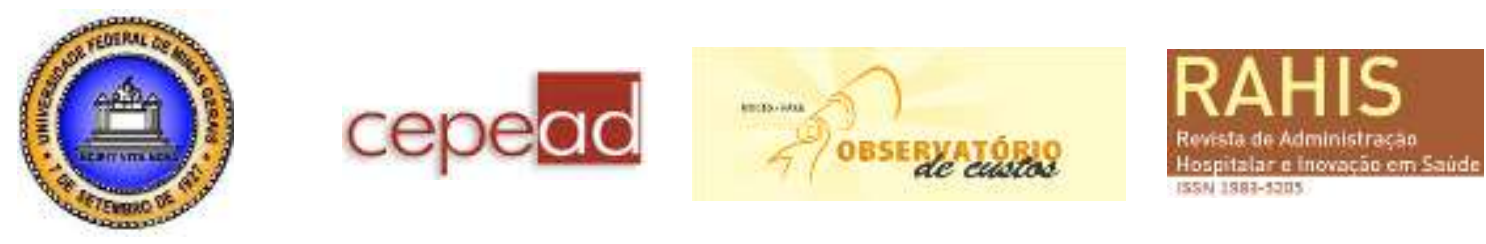

considerar o princípio de redundância dos dados obtidos, como considerado por pesquisadores qualitativos quando em campo (e.g. GODOI; MATTOS, 2006; GODOY, 2006).

O trabalho de campo ocorreu durante o ano de 2011. Reforça-se também que se utilizou de entrevistas baseadas em roteiro, junto aos representantes das organizações a serem pesquisadas, como principal técnica para coleta de dados, por essa estar amplamente presente em investigações sociais, a propiciar um sistema comunicativo dinâmico, que se retroalimenta a partir da interação entre pesquisados e pesquisadores.

Frisa-se que a pesquisa, em sua fase de análise de dados, lançou mão da abordagem qualitativa em sua condução, bem como a técnica de análise de conteúdo, tendo o interpretativismo como paradigma (GODOY, 2005; HATCH; YANOW, 2005; BARDIN, 2000; DAFT; WEICK, 1984). A utilização da técnica de Path Dependence, também observada durante a pesquisa, condiz com sua natureza qualitativa e, principalmente, com o intuito de analisar os fenômenos dependentes da trajetória do empreendimento econômico solidário selecionado.

Hoff (2008, p. 408), a partir da análise de algumas definições referente a Path Dependence, conceitua o termo como sendo "um fenômeno que pode ser observado em processos históricos ligados à evolução de algo, condicionado pela percepção de algumas características ou comportamentos específicos". Consoante à pesquisadora, a Path Dependence ocorre quando um dado sistema apresentar resultados que estejam relacionados a condições iniciais, sendo os resultados obtidos dependentes das escolhas feitas em períodos intermediários ocorridos entre a condição inicial e o próprio resultado observados e, essas escolhas tenham determinando, em parte, o desenvolvimento dos eventos futuros.

A descrição da trajetória histórica da COOPCAPS contempla ao objetivo assumido pelos pesquisadores em sua investigação. Neste trabalho, optou-se por registrar a trajetória do empreendimento econômico solidário pesquisado a partir de 5 blocos descritivos: surgimento, participantes, incubação, dificuldade e soluções, resultados alcançados. Em decorrência ao registro da trajetória histórica tendo esses blocos, houve a confecção do framework correspondente, tendo em seu bojo a evidenciação das condições antecedentes, momentos críticos, sequências auto-reforçantes e reativas, como também os resultados. A partir da evidenciação da trajetória histórica da COOPCAPS foi possível analisar esse EES sob os construtos da inovação social.

Por fim, frisa-se que durante os primeiros contatos com os sujeitos da pesquisa, questões éticas foram atentadas (CRESWELL, 2007; COOPER; SCHINDLER, 2003), a considerar o direito de participação voluntária - como também o de desistir -, a permissão da gravação de áudio das entrevistas, a exposição dos objetivos da pesquisa, possibilidade de fazer perguntas, de obter uma cópia dos resultados e de ter a privacidade respeitada.

\section{Resultados}

\section{Condições Antecedentes para a Criação da COOPCAPS}

O surgimento da Cooperativa Social do Centro de Atenção Psicossocial Ltda (COOPCAPS) está intricado com o tratamento de pacientes com transtornos mentais oferecido pelo Centro de Atenção Psicossocial (CAPS) da cidade de Fortaleza/CE, tendo uma profissional do CAPS como ator de destaque por, a partir da percepção das habilidades existentes no grupo 

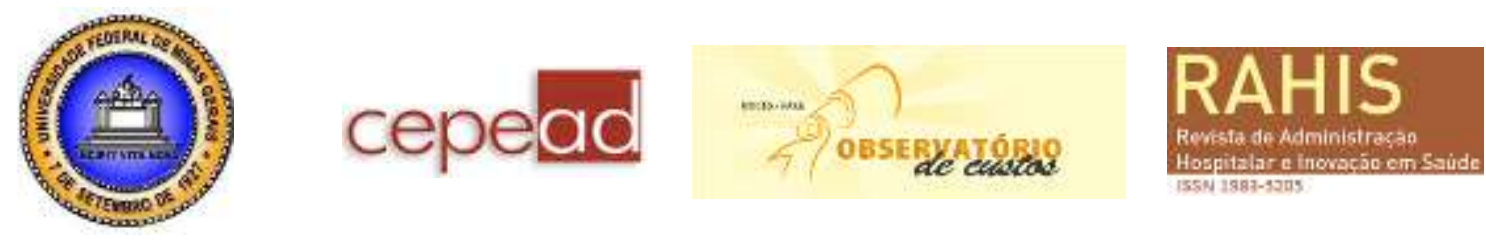

de pacientes da terapia ocupacional, ter tido a ideia de formar uma cooperativa de artesanato e buscado ajuda de uma incubadora tecnológica de cooperativas populares (ITCP).

As motivações para a formação da COOPCAPS condisseram, inicialmente, com a percepção, por parte da terapeuta ocupacional do grupo em tratamento no CAPS, referente às potencialidades dos pacientes em desenvolver trabalhos com o artesanato. Também, em paralelo a essa percepção, deu-se como motivação dos profissionais do CAPS o enfrentamento do problema para atender a demanda pelos serviços do centro, visto a quantidade crescente de pacientes e a existência de poucos terapeutas do CAPS.

Até então, as percepções das potencialidades do grupo e do possível enfrentamento para o problema de atendimento da demanda pelos serviços do CAPS, que foram motivações iniciais que repercutiram no surgimento da ideia de constituição de uma cooperativa, partiu de uma profissional do CAPS e não, necessariamente, do grupo em tratamento, esse que hoje corresponde aos responsáveis pela gestão e funcionamento da COOPCAPS.

A motivação desse grupo correspondeu, após o compartilhamento e aceitação da ideia proposta pela terapeuta ocupacional do CAPS junto a uma ITCP, com a vontade do grupo em externar que são capazes de aprender, de trabalhar e de conviver como pessoas normais e, dessa forma, enfrentar o preconceito de que são loucos, por terem sido diagnosticados como pessoas que sofrem com transtornos mentais.

A escolha do que produzir partiu do aproveitamento dos conhecimentos, habilidades e experiências dos participantes do grupo de terapia ocupacional, daqueles que já trabalharam ou que trabalhavam com o artesanato. Fato compatível aos objetivos do tratamento terapêutico realizado pelo CAPS, por representar o possível melhoramento da autoestima dos envolvidos, mediante o trabalhar as suas potencialidades.

\section{Os Participantes do Empreendimento em Questão}

Os participantes da COOPCAPS têm suas vidas marcadas pela marginalização que, muitas vezes, decorre da rejeição e do preconceito por parte de seus próprios familiares, que os têm como loucos. Assim, os sentimentos de abandono e de solidão foram e continuam sendo aquilo que os participantes, ao longo de suas vidas, têm de lidar.

Eu tinha um problema de depressão, muito sério. Aí eu passei muitos anos mesmo com a depressão e nunca conseguia melhorar. Me sentia abandonada pela família, me sentia só e era fora de sério o meu problema. Só vivia chorando. [...] Desmaiava, caia, meu corpo é todo marcado porque eu caia nas ruas (COOPCAPS.03).

Os sentimentos de abandono e solidão, comuns a maioria dos participantes da COOPCAPS, agravavam os transtornos mentais por eles enfrentados, especialmente nos casos de depressão. Contudo, os participantes da COOPCAPS procuraram ajuda médica para o tratamento de seus problemas de saúde e encontraram no CAPS o apoio necessário para o lidar, de maneira adequada, com os transtornos mentais enfrentados.

Partindo da rejeição familiar e do desconhecimento do que ao certo estava ocorrendo, a situação dos participantes da COOPCAPS, antes da criação do empreendimento econômico solidário, conotava num contexto de marginalização e sofrimento, até quando diagnosticados como pessoas que sofrem com transtornos mentais.

Às vezes você tem um transtorno, uma depressão. Às vezes você próprio não sabe, assim: problema de família, problema de marido, problema de filhos e você chega 
num problema de depressão. Só que você, às vezes, não conhece que é isso, nem a sua família conhece. Quando chega num determinado tempo, que chega alguém que ver que você realmente está naquele estado, que é depressão. [...] Então, eu já presenciei muitas vezes e também sou uma delas, de pessoas chorarem lá no CAPS porque tem depressão e a família tem vergonha, a família não acompanha nos dias das consultas, que eu acho uma injustiça. Eu sou uma das tais, eu vou sozinha. Isso, às vezes, machuca (COOPCAPS.02)

Iniciado o tratamento no CAPS, os participantes da COOPCAPS concentraram-se em seguir as recomendações médicas e em participar das sessões de terapia ocupacional, visando a melhora de seus estados de saúde. Ou seja, antes da criação da COOPCAPS, a vida dos cooperados limitava-se a seguir o tratamento contra os transtornos mentais. Quando em tratamento, passaram a apresentar melhoras e durante os encontros do grupo de terapia ocupacional, tiveram a oportunidade de desenvolver habilidades referentes ao artesanato. Nesses momentos, algumas pessoas puderam não só demonstrar o que já faziam, como também ensinar e aprender variados tipos de artesanato.

\footnotetext{
Porque dentro do grupo de terapia ocupacional, o objetivo da terapeuta é trabalhar as habilidades, para melhorar a autoestima. Com isso, foi descobrindo as habilidades de cada um e aproveitando os que já tinham antes de entrar no grupo de terapia ocupacional, aqueles que já trabalhavam com artesanato antes de entrarem no grupo. Eu quando entrei, já fazia, ela também já fazia. [...] A gente foi repassando, ensinando a outras pessoas, aprimorando para fazer tudo correto (COOPCAPS.02).
}

O grupo que participava da terapia Ocupacional oferecida pelo CAPS era formado por 20 pessoas com diferentes tipos de transtornos mentais. Quantidade equivalente ao número inicial de sócio-cooperados que participaram do processo de incubação da COOPCAPS. Com o passar dos anos, apesar da saída de algumas pessoas, por motivos de saúde, a quantidade de participantes veio a aumentar: 20 participantes antes e durante o processo de incubação; 30 participantes quando na fundação do empreendimento, em 2005. Atualmente, a COOPCAPS conta com 39 sócio-cooperados e um total de mais de 51 usuários.

Ressaltou-se que os sócio-cooperados da COOPCAPS não correspondem exclusivamente a pessoas com transtornos mentais, mas também conta com a participação de alguns familiares das pessoas em tratamento no CAPS. No tocante a abrangência territorial, segundo os sujeitos da pesquisa, a COOPCAPS consegue abranger toda a cidade de Fortaleza/CE, por seus participantes residirem em variados bairros.

[...] A gente viu, no início, todo mundo desse grupo que está aqui, que as pessoas eram tristes, ficavam chorando e reclamando, às vezes nem falavam um com o outro, ficava no grupo e cada um fazia lá o seu, mal um olhava para o outro. E hoje a gente ver que todo mundo fala, que todo mundo se comunica e tem capacidade. E ver eles fazerem o trabalho e ter orgulho quando terminam, que viu que aquele trabalho deles tem resultado. Quando vai para o CAPS sabe que vai para um tratamento e quando vem para cá, sabe que, ganhando um dinheiro ou não, vem fazer um trabalho. Então, eles já sabem que vêm trabalhar (COOPCAPS.01).

Questionados sobre se os sócios gostam do trabalho desenvolvido em cooperativa, os sujeitos da pesquisa revelaram que sim, tendo como justificativa para sustentar tal afirmação, o fato dos trabalhos por eles desenvolvidos diferenciar-se do momento de tratamento no CAPS. 

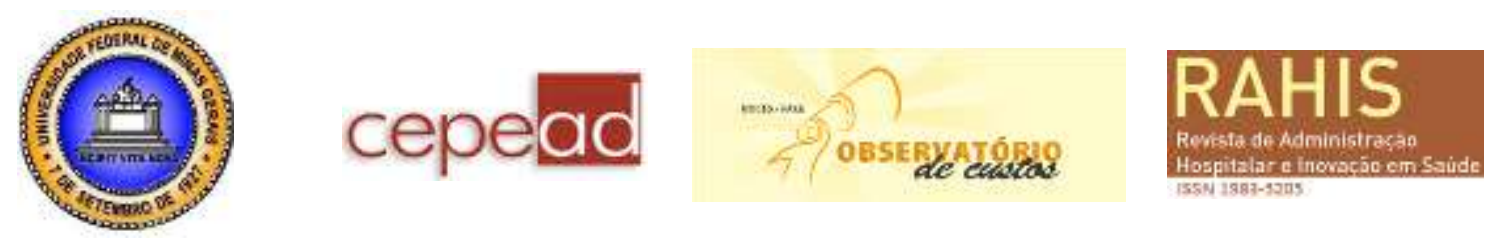

Isso representa superação, ainda que não traga consistentes resultados financeiros, como observou a COOPCAPS.01.

\section{O Processo de Incubação da COOPCAPS}

A aproximação do grupo com uma ITCP foi intermediada pela terapeuta ocupacional do CAPS e não pelas pessoas que participavam do grupo de terapia. Tanto a ideia para a formação da COOPCAPS, como também a busca pela incubadora não partiu daqueles que hoje gerem o empreendimento criado. O que, numa perspectiva crítica, poderia tornar questionável o papel ativo dos participantes do EES e se a organização responsável pelo processo de incubação estaria acessível à aproximação desse público.

Idealiza-se (CALBINO; PAES DE PAULA, 2011; BARRETO; PAES DE PAULA, 2009; GIRELLI, 2009; CAEIRO, 2008; CRUZ, 2006; TARDIF, 2005; CLOUTIER, 2003; PETITCLERC, 2003) que os atores sociais assumam posicionamentos ativos frente a situações de marginalização vivenciadas. Em outras palavras, que sejam os próprios que procurem soluções para os problemas enfrentados. No caso da COOPCAPS, observou-se que o idealizado ocorreu quanto à busca por tratamento dos transtornos mentais e que, posteriormente, pela sensibilização do grupo, houve o auxílio exógeno rumo à incubação.

O processo de incubação durou aproximadamente 1 ano, de acordo com os sujeitos da pesquisa. No ano de 2005, a COOPCAPS foi graduada e desde então já se passaram mais de 5 anos, período superior a taxa crítica de mortalidade de organizações no país (SEBRAE, 2007; RTS, 2005) e o que qualificaria o processo de incubação fornecido pela ITCP.

A incubação valeu-se de encontros presenciais, 2 vezes por semana, ocorrendo 1 vez por semana nas dependências da ITCP e 1 vez no CAPS. Desse processo, os sujeitos da pesquisa destacaram o curso de cooperativismo (que atualmente faz parte dos critérios para a admissão de um novo sócio), a assessoria para realizar a legalização, divulgação e preparação total da gestão da COOPCAPS.

Os sujeitos da pesquisa avaliaram que "valeu a pena" a aproximação com a incubadora e ter passado pelo processo de incubação. Ainda, reforçaram que sem o apoio da incubadora, a COOPCAPS não teria sido fundada e eles não estariam como estão hoje. O contato entre a COOPCAPS e a ITCP ainda persiste, sendo a incubadora responsável pela contabilidade da cooperativa e se coloca a disposição para ajudar em eventuais demandas da cooperativa.

\section{Dificuldades e Soluções Deparadas Durante o Amadurecimento Organizacional}

Com a criação da COOPCAPS, seus participantes tiveram que encarar alguns problemas, dentre eles: escassez de recursos monetários, dificuldade de relacionamento entre os participantes, limitações ocasionadas por problemas de saúde e de comercialização. A ausência de recursos financeiros foi um dos problemas que desde o início do trabalho com o artesanato, os participantes da COOPCAPS vieram a enfrentar. Segundo os sujeitos da pesquisa, não havia dinheiro para comprar matéria-prima e para iniciar a produção.

No entanto, seguiram meios alternativos, muitas vezes, pedindo doação de retalhos para poderem produzir peças que tinham o fuxico como "carro-chefe" e, desse modo, iniciaram a produção. Com os resultados do que conseguiam vender, investiam em outras ideias visando à comercialização do artesanato por eles produzido. 

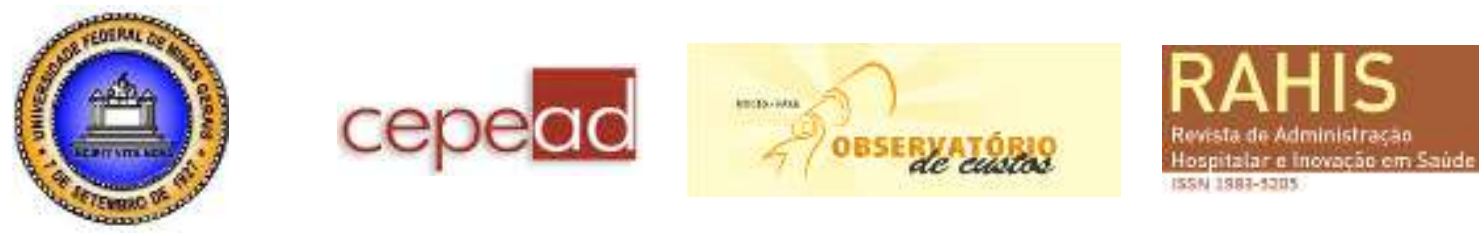

[...] A gente também não tinha dinheiro para os produtos, tanto é que arranjava retalhos. Aí como eu já sabia fazer fuxico, fomos arranjar materiais para fazer fuxico e, justamente, nosso carro-chefe é fuxico. Tudo o que nós fazemos tem que ter o fuxico no meio (COOPCAPS.02).

Contaram também que outras despesas que a COOPCAPS poderia ter - como as referentes a uma sede e sua manutenção - foram assumidas por apoiadores: CAPS com a concessão temporária (2004 a 2007) de uma sala para as atividades do empreendimento; Prefeitura Municipal de Fortaleza, com o pagamento do aluguel, água, energia da atual sede e, ainda, fornece o vale-transporte para os sócio-cooperados.

A COOPCAPS continua a contar com doações de materiais para a produção, oriundas de diferentes fontes, até mesmo conseguidas por intermédio da incubadora. Durante a entrevista, percebeu-se a grande importância dos apoiadores para a criação e continuidade da COOPCAPS, vez que tal apoio, em especial os concedidos por via de doações, torna os apoiadores mais do que organizações parceiras, mas sim mantenedores. O que por um lado explicaria a continuidade das atividades da COOPCAPS, mas por outro desembocaria numa relação de dependência entre o empreendimento e seus "parceiros".

Quando questionadas sobre os problemas vivenciados no início da COOPCAPS, uma das entrevistadas revelou que houve muitos, mas com a ajuda de algumas organizações parceiras a COOPCAPS conseguiu sobreviver aos problemas iniciais. O respeito, a atenção e o diálogo foram elementos que favoreceram o aprender a conviver e, em decorrência, minimizam as dificuldades de relacionamento, pois um sujeito da pesquisa alertou que "as pessoas que são menos alteradas não devem ignorar as pessoas mais alteradas" (COOPCAPS.02).

As dificuldades referentes ao relacionamento entre os cooperados foram apresentadas como recorrentes, seja com a entrada de um novo sócio-cooperado, seja decorrente de debates acerca da contribuição de cada um, com os materiais de limpeza e para a alimentação, principalmente. No entanto, quanto ao trabalho da COOPCAPS, as dificuldades de relacionamento não vêm a se sobressair, pois todos acabam cooperando.

Não só por transtornos mentais os participantes da COOPCAPS vêm a ser acometidos. Outros problemas de saúde surgiram, além do possível agravamento dos transtornos sofridos por causa de fatores externos à COOPCAPS, os quais limitam a participação e, até mesmo, impõe o afastamento dos sócio-cooperados. Sobre isso, foi comentado pelos sujeitos da pesquisa que houve sócio-cooperados que não conseguiram se adaptar ao trabalho em cooperativa e, dessa forma, não puderam continuar a trabalhar na COOPCAPS.

Um dos mais preocupantes problemas enfrentados pela COOPCAPS, atualmente, concentra-se no âmbito da comercialização. Foi revelado que o empreendimento possui dificuldades de realizar vendas, como também na precificação de seus produtos. O agravamento da dificuldade com as vendas dos produtos ocorre pela falta de condições da COOPCAPS para montar um ponto de vendas para exposição e comercialização do artesanato que produzem.

Em contrapartida, participaram de um projeto desenvolvido pela ITCP, denominado Mercado Solidário, no qual a COOPCAPS dividiu um ponto de vendas com outros EES, numa conhecida e movimentada avenida da cidade de Fortaleza/CE. No entanto, o Mercado Solidário alcançou tímidos resultados, o que repercutiu na sua descontinuidade. Com o término do Mercado Solidário, a COOPCAPS firmou parceria com um outro empreendimento econômico solidário para a comercialização de seus produtos na loja desse empreendimento.

Atualmente a direção da COOPCAPS planeja montar uma loja em sua sede, aproveitando um dos ambientes da sede para tanto. Porém, a direção alega que as limitações 
financeiras da cooperativa fazem com que o plano de constituir uma loja dentro da sede não seja, no curto prazo, possível.

A dificuldade financeira veio à tona mais uma vez. O alcance de recursos como consequência das vendas do que é produzido pela COOPCAPS assume papel, no mínimo, intrigante. Ao mesmo tempo em que há a necessidade por resultados financeiros, há a dificuldade das vendas e também a desvalorização do artesanato, diretamente refletida na precificação adotada pela COOPCAPS.

Fizemos uma calça de fuxico, uma encomenda para um professor que é de circo... Quando fomos para um evento, aí a gente achava que ele ia estar lá presente e levamos a calça. [...] A gente pediu R \$ 300,00, só que ele achou caríssimo. Mas o preço que a gente coloca não é o preço real que deveria ser do produto, porque se fosse colocar, com certeza, a gente teria dificuldade de vender (COOPCAPS.01).

A calça de fuxico sintetiza alguns problemas comerciais enfrentados pela COOPCAPS, dentre eles, a desvalorização do artesanato produzido e a dificuldade de vendas. Apesar da calça de fuxico ter sido encomendada, e está pronta há alguns meses, até o momento desta pesquisa, ainda continua a espera por seu demandante.

Para agravar o mix de a) necessidade por dinheiro, b) dificuldade de vendas e c) desvalorização do que produz, a desvalorização acaba ocorrendo não só por parte dos clientes, mas também internamente. Os sujeitos da pesquisa revelaram que pela dificuldade das vendas, precificam, de maneira consciente, seus produtos a adotar preços abaixo dos preços de custo e, apesar disso, o empreendimento ainda não consegue vender facilmente.

\section{Resultados Mais Significativos na Vida da COOPCAPS}

Os resultados alcançados com a criação da COOPCAPS remetem-se a ganhos sociais e de melhoria da qualidade de vida de seus participantes. Dentre os resultados, revelados pelos sujeitos da pesquisa estão os vínculos criados entre os sócio-cooperados a partir do aprender a conviver com diferentes pessoas, com diferentes transtornos.

Eu sou piada das pessoas da família que dizem que eu vivo trabalhando de graça, aí o que respondo é isso: o que eu ganho lá é mais importante que o dinheiro, porque com o dinheiro não compro a minha saúde. E lá dentro o que eu ganho é a saúde e sem a saúde não sou ninguém [...] (COOPCAPS.03).

Os vínculos criados aliados ao trabalho em cooperativa e ao tratamento no CAPS resultaram na realização de sonhos e na elevação da autoestima das pessoas envolvidas que, a cada dia, passaram a se valorizar e, dessa forma, a enfrentar o preconceito, inclusive o preconceito familiar.

Tenho prazer de dizer que faço parte da COOPCAPS, porque foi lá o que eu consegui o que eu sou hoje. Aprendi a me dar valor, aprendi a viver e, até ser dona de casa eu aprendi. Nem ao pé do fogão eu ia, que era proibida pelo médico e hoje em dia eu sou dona da minha casa. Voltei a estudar. [...] Quando foi em 2006, eu voltei, repeti a $8^{\mathrm{a}}$ série e, em 2009, terminei o ensino médio (COOPCAPS.03).

[...] No meu caso, eu parei de tomar o remédio, até alta os médicos me deram, mas me deixaram como representante dos usuários, porque eu mesmo pedi para ficar que eu me sentia muito bem aqui dentro e não queria sair daqui (COOPCAPS.03). 
Além disso, afirmaram que nesse EES há o reconhecimento do esforço de todos os sócios envolvidos e, que elas se sentem reconhecidas. Foi falado que o reconhecimento na COOPCAPS é realizado tendo a produção e a participação frequente como principais critérios considerados, sendo o reconhecimento expresso sob a forma de elogios e no momento de divisão dos resultados da atividade econômica.

O "se sentir bem" (COOPCAPS.02 e COOPCAPS.03) e a "felicidade" (COOPCAPS.01) foram fatos pontuados como recorrentes, relacionados ao reconhecimento dos esforços dos sócio-cooperados e que incentivam a busca por fazer melhor. Os sujeitos da pesquisa também atribuíram a melhoria do estado de saúde dos sócio-cooperados ao conjunto dos resultados mais significativos alcançados pela COOPCAPS, tendo como exemplo maior o fato de um dos participantes ter recebido alta médica e não precisar mais tomar os medicamentos controlados como antes.

O pedido para continuar participando das atividades de uma das sócias da COOPCAPS foi movido pelo reconhecimento do que o trabalho da cooperativa representa e do que esse trabalho ajudou a conquistar, além do valor subjetivo impresso no fato de se sentir "melhor dentro da cooperativa, do que dentro de casa" (COOPCAPS.03). As sócio-cooperadas da COOPCAPS torcem por um futuro melhor para o EES e que no futuro a COOPCAPS "esteja bem grande, bem crescida, tanto com mais gente, como financeiramente também" (COOPCAPS.01).

Exprimiram, ainda, o desejo de que os resultados do empreendimento sejam resultados econômicos e não apenas sociais, pois as sócias reclamaram dizendo que "espera que melhore, porque a gente não pode viver sem um ganho" (COOPCAPS.03), pois "eles precisam de uma renda" (COOPCAPS.02). Referente ao futuro de cada sócia, as entrevistadas foram categóricas ao afirmarem que desejam "estar bem" e que querem se "sentir da mesma maneira" que se sentem atualmente.

\section{Discussão}

A figura 1 sintetiza a trajetória histórica da COOPCAPS, reforçando os momentos críticos, as sequencias auto-reforçantes, as sequências reativas e os resultados alcançados ao longo dos 8 anos de vida da cooperativas (2003-2008). Pode-se iniciar a discussão da inovação social a partir do que de fato repercutiu na criação da COOPCAPS, vendo que existia a consciência das situações insatisfatórias e a vontade das pessoas para superá-las. 
Fígura I - Trajetória Jistórica da COOPC.APS

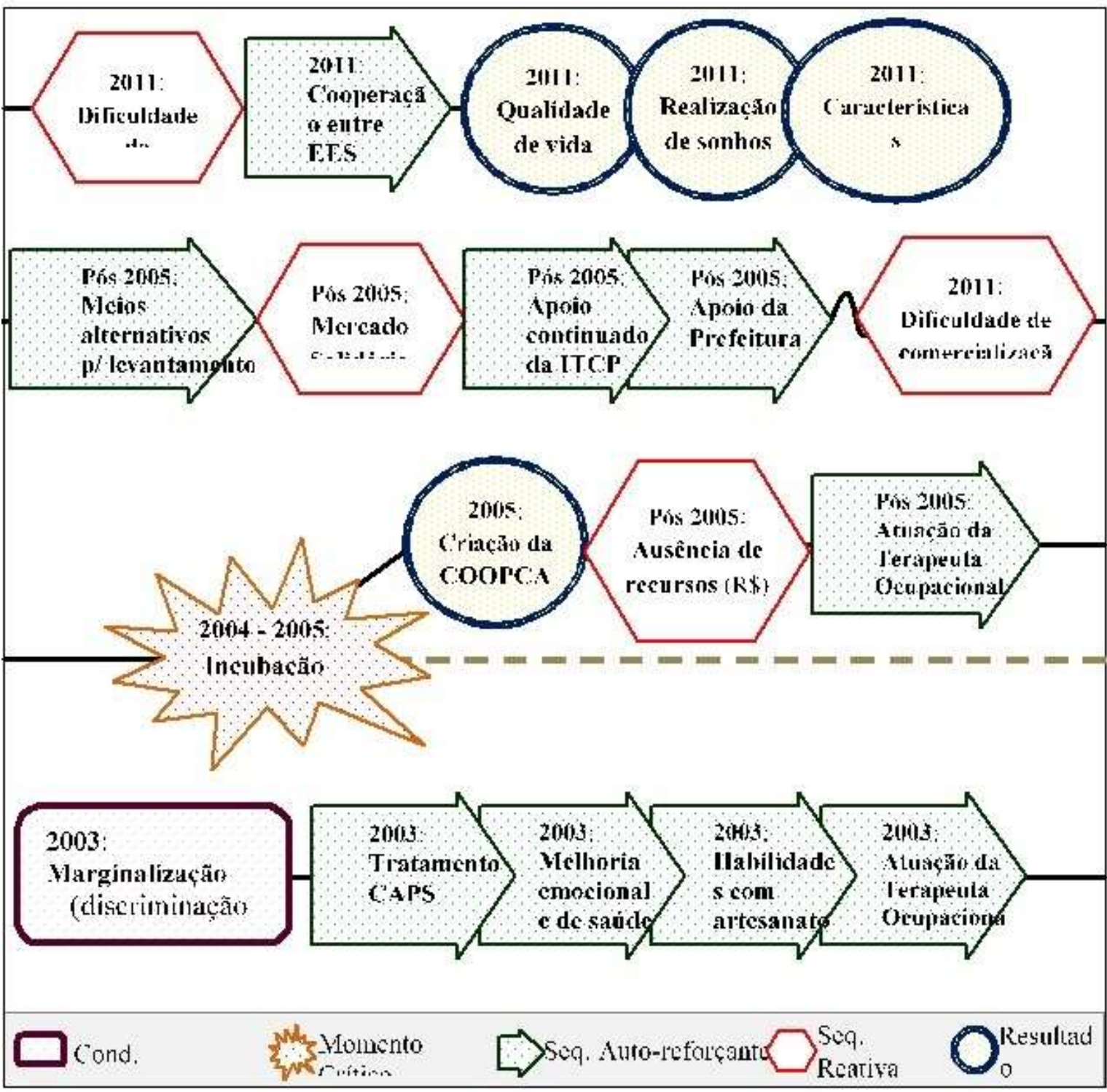

Fonte: elaborado a partir dos dados da pesquisa.

Tardif (2005) e Cloutier (2003) defendem que a inovação do tipo social é precedida pela necessária conscientização de um problema. No caso da COOPCAPS, houve o reconhecimento da situação de marginalização na qual os indivíduos se encontravam, sendo o preconceito reconhecido como um dos principais problemas que agravava a situação de marginalização das pessoas envolvidas.

A conscientização da situação de marginalização refletiu-se na motivação para a criação do EES, o que seriam a própria solução, um meio para a defesa de interesses (PETITCLERC, 2003) e de alcance de um bem-estar dos indivíduos (MAURER, MARQUESAR, SILVA, 2010; CLOUTIER, 2003).

Para a criação da COOPCAPS como solução, houve a mobilização de diferentes atores sociais, desde a terapeuta ocupacional do CAPS ao envolvimento de instituições 

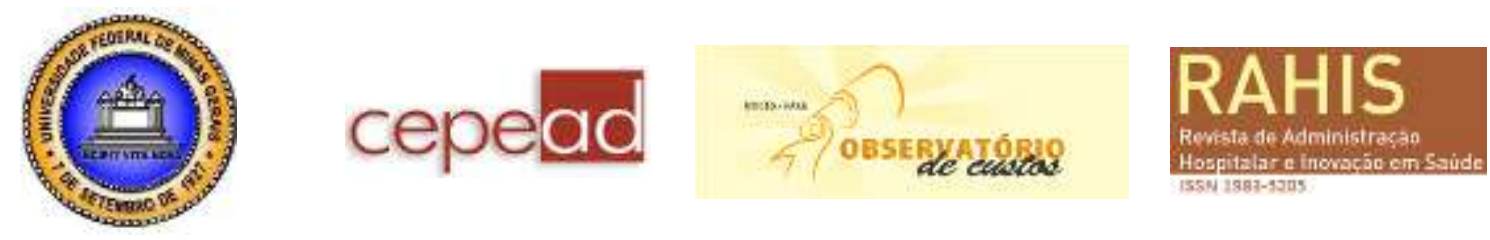

governamentais e de uma ITCP. Nesse sentido, pode-se comprovar que o processo de criação da COOPCAPS - como inovação - necessitou da atuação de uma diversidade de atores, como defendido na literatura por Tardif (2005), Cloutier (2003), Petitclerc (2003).

O valer-se de dinâmicas sociais (TARDIF, 2005) e do convívio com os outros, seja em rede, seja participando de movimentos sociais (CLOUTIER, 2003; PETITCLERC, 2003), resultou para os EES pesquisados num processo coletivo de aprendizagem e de criação do conhecimento (CLOUTIER, 2003). O aprendizado e o conhecimento são reforçados pelas experiências conquistadas, sendo estes elementos balizadores da tomada de decisões e que permitem a COOPCAPS continuar funcionando.

Assim, a COOPCAPS corresponde a uma nova forma adotada a fim de responder a situações insatisfatórias. Sobre esse ponto de vista, viria a atender as definições de inovação social proferidas por Cloutier (2003) e por Lévesque (2002). Os resultados alcançados com a criação e desenvolvimento da COOPCAPS assume natureza tangível e intangível. Os resultados tangíveis remetem-se a quantidade de pessoas que participaram e participam desse empreendimento, conseguindo conquistar uma profissão, e com o fruto de seu trabalho, o seu sustento, ainda que não de forma plena.

Os resultados intangíveis, por sua vez, remetem-se a questão do sentimento de pertença, do sentir-se bem, de amizade e de todo o significado atribuído ao trabalho pelos sóciocooperados pesquisados. Um dos principais resultados intangíveis coincide, considerando os relatos das sócio-cooperadas da COOPCAPS, com um novo pensamento, o qual imprime o sentido de mudança nas relações dos indivíduos e o trabalho por eles executados. Pois o trabalho deixou de ser tido como algo popularmente considerado desagradável e passou a ter uma maior importância por esses sócios fazerem o que amam e, dessa maneira, se sentem bem e reconhecidos. O trabalho passou a ser tido como algo agradável e enriquecedor para vida.

\section{Conclusão}

Sob o olhar da inovação social a COOPCAPS representa ser a própria inovação, pois consiste na nova solução encontrada pelos indivíduos, com o apoio de distintas entidades da sociedade, motivados para o enfrentamento da situação de marginalização. Apesar de ter passado por um processo de incubação numa ITCP, tendo assessoria para sua constituição legal e desenvolvimento de sua gestão, a COOPCAPS sofre dificuldades de comercialização e financeira. Situação que veio a questionar se a evidenciação da sua viabilidade econômicofinanceira foi devidamente realizada pela incubadora.

Outro fato a ser atentado é o estabelecimento e manutenção de uma relação de dependência da COOPCAPS para com seus "parceiros", que se comportam como vitais mantenedores. Numa reflexão sobre isso, há a consciência de que após o processo de incubação era esperado que a COOPCAPS conseguisse manter-se com os resultados de sua ação econômica. Em consequência, não houvesse tamanha dependência.

Chegou-se a imprimir um sentido paradoxal, que não justificaria, por um lado, o que ocorreu - relação de dependência - em choque com o resultado que era esperado: EES, que, partindo dos princípios da Economia Solidária, conseguisse sustentar-se em ambiente de mercado, sobretudo de maneira autônoma e ativa. Evidenciação que endossa que os EES, mesmo sendo tidos como incipientes, muito tem a se discutir. Dessa forma, tomou caráter relevante a apresentação de sugestões para a condução de próximas pesquisas a confrontar, por 

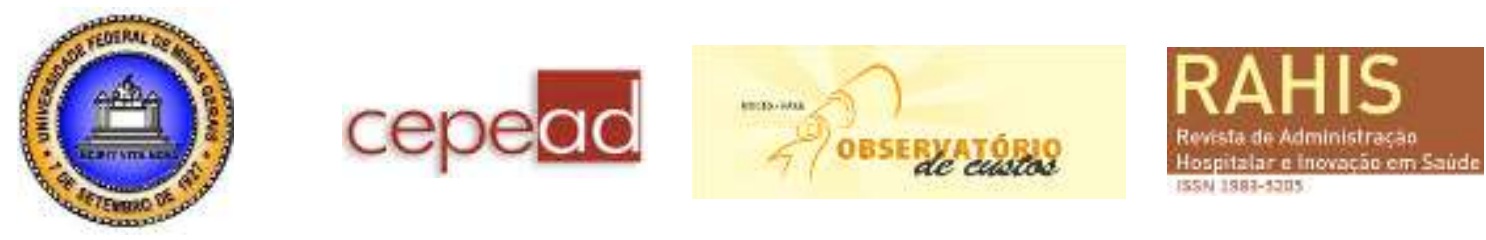

exemplo, a necessidade por parcerias e a possível ocorrência de relação de dependência entre os parceiros com o princípio de autogestão da Economia Solidária.

\section{Referências}

ATTIE, J. P. Organizações solidárias de produção: subversão ou submissão ao capital? Uma análise sobre as possibilidades da emancipação pelo trabalho. Curitiba. Dissertação (Mestrado em Administração). Universidade Federal do Paraná, 2007.

BARDIN, L. Análise de conteúdo. Rio de Janeiro: Edições 70, 2000.

BARRETO, R. O.; PAES DE PAULA, A. P. Os dilemas da economia solidária: um estudo acerca da dificuldade de inserção dos indivíduos na lógica cooperativista. Cadernos Ebape. Rio de Janeiro, v. 7, n. 2, p. 199-213, jun. 2009.

BOAVA, D. L. T.; MACEDO, F. M. F. Empreendedorismo explicitado à maneira dos filósofos. In: ENCONTRO DE ESTUDOS EM ESTRATÉGIA, V, 2011, Porto Alegre. Anais... Porto Alegre: ANPAD, 2011. CD-ROM.

BRUM, A. L. Economia solidária: elementos para compreensão. Desenvolvimento em Questão, Ijuí, v. 1, p. 217-228, jan./ jul. 2003.

CAEIRO, J. M. C. Economia social: conceitos, fundamentos e tipologia. Revista Katál, Florianópolis, v. 11, n 1, p. 61-72, jan./jun. 2008.

CALBINO, D.; PAES DE PAULA, A. P. Embates sobre a neutralidade da gestão e a ressignificação do conhecimento gerencial nas incubadoras tecnológicas de cooperativas populares. In: ENCONTRO DE ESTUDOS ORGANIZACIONAIS, VI, 2010, Florianópolis. Anais... Florianópolis: Anpad, 2010. CD-ROM.

CANÇADO, A. C.; CANÇADO, A. C. M. G. Incubação de cooperativas populares: metodologia dos indicadores de incubação. 2. ed. Palmas: Futura, 2009.

CANÇADO, A. C.; VIEIRA, N. S.; CANÇADO, A. C. M. G. Incubação de cooperativas populares: um estudo de multicasos no Bico do Papaguaio/TO. In: COLÓQUIO INTERNACIONAL SOBRE PODER LOCAL, XI, 2009, Salvador. Anais... Salvador: UFBA, 2009. CD-ROM.

CLOUTIER, J. Qu'est-ce que l'innovation sociale? Collection études théoriques, n. ET0314, nov. 2003.

COOPER, D. R.; SCHINDLER, P. S. Métodos de pesquisa em administração. 7. ed. Porto Alegre: Bookman, 2003. 


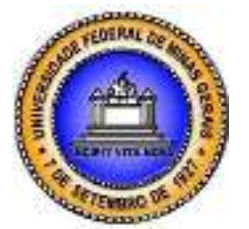

CRESWELL, J. W. Estratégias de redação e considerações éticas. In: CRESWELL, J. W. Projeto de pesquisa qualitativa: métodos qualitativos, quantitativos e misto. Porto Alegre: Bookman, 2007. Cap. 3, p. 64-83.

CRUZ, A. C. M. Políticas públicas para a economia solidária: fronteira entre política social e política para o desenvolvimento local. Revista Sociedade em Debate, Pelotas, v. 12, n. 1, p. 117-131, jun. 2006.

DAFT, R. L.; WEICK, K. E. Toward a model of organizations an interpretation model. Academy of Management Rewiew, v. 9, n.2, p. 284-295, 1984.

DRUCKER, P. F. Inovação e espírito empreendedor (entrepreneurship): prática e princípios. São Paulo: Pioneira Thomson, 2003.

GAIGER, L. I. A economia solidária diante do modo de produção capitalista. Caderno CRH, Salvador, v. 16, n. 39, p. 181-211, jul./ dez. 2003.

GIL, A. C. Como elaborar projetos de pesquisa. 4. ed. São Paulo: Atlas, 2002.

GIRELLI, S. Incubadoras sociais: perspectivas e desafios na consolidação da economia solidária. In: CONGRESSO DA REDE DE ITCPS, II, 2009. Anais... São Paulo: Rede de ITCPs, 2009. CD-ROM.

GODOI, C. K.; MATTOS, P. L. C. L. Entrevista qualitativa: instrumento de pesquisa e evento dialógico. In: GODOI, C. K.; BANDEIRA-DE-MELO; R.; SILVA, A. B. (orgs). Pesquisa qualitativa em estudos organizacionais: paradigmas, estratégias e métodos. São Paulo: Saraiva, 2006. Cap. 10, p. 301-320.

GODOY, A. S. Estudo de caso qualitativo. In: GODOI, C. K.; BANDEIRA-DE-MELO; R.; SILVA, A. B. (orgs). Pesquisa qualitativa em estudos organizacionais: paradigmas, estratégias e métodos. São Paulo: Saraiva, 2006. Cap. 4, p. 115-143.

Refletindo sobre critérios de qualidade da pesquisa qualitativa. Revista Eletrônica de Gestão Organizacional, v. 3, n. 2, p. 85-94, mai./ago. 2005. GOLLO, S. S. Inovação e estratégia de cooperação competitiva: estudo de caso da indicação de procedência Vale dos Vinhedos - Serra Gaúcha/RS. Porto Alegre. Tese (Doutorado em Administração). Universidade Federal do Rio Grande do Sul, 2006.

GOERCK, C.; BULLA, L. C. Gestão coletiva: uma possibilidade existente em experiências de economia popular solidária no Vale do Rio Pardo. Estudo \& Debate, Lajeado, v. 17, n. 1, p. 75-90, 2010.

HATCH, M. J.; YANOW, D. Organization theory as an interpretive science. In: TSOUKAS, H.; KNUDSEN, C. (Eds). The Oxford handbook of organization theory. Inglaterra: Oxford University Press, 2005, p. 63-87. 
HOFF, D. N. A construção do desenvolvimento sustentável através das relações entre as organizações e seus stakeholders: a proposição de uma estrutura analítica. Porto Alegre. Tese (Doutorado em Agronegócios). Universidade Federal do Rio Grande do Sul. 2008.

LEITE, M. P. A economia solidária e o trabalho associativo: teorias e realidades. Revista Brasileira de Ciências Sociais, v. 24, n. 69, p. 31-51, fev. 2009.

LÉVESQUE, B. Les entreprises d'économie sociale, plus porteuses d'innovations sociales que les autres? Collection études théoriques, n. ET0205, mai. 2002.

MAURER, A. M.; MARQUESAN, F. F. S.; SILVA, T. N. As relações entre as inovações sociais e o desenvolvimento sustentável: o caso da Univens. In: ENCONTRO DA ANPAD, XXXIV, 2010. Anais... Rio de Janeiro: ANPAD, 2010. CD-ROM.

MTE. Ministério do Trabalho e Emprego. Atlas da economia solidária no Brasil: 2007. Portal do Trabalho e Emprego. Brasília, DF, 2010. Disponível em: <http://www.mte.gov.br/sistemas/atlas/atlases.html>. Acesso em 19 de out. 2012.

O que é Economia Solidária? Portal do Trabalho e Emprego. Brasília, DF, 2009a. Disponível em: <http://www.mte.gov.br/ecosolidaria/ecosolidaria_oque.asp>. Acesso em 18 de out. 2012.
Os empreendimentos econômicos solidários. Portal do Trabalho e Emprego. Brasília,
DF, 2009b. Disponível em: <http://www.mte.gov.br/ecosolidaria/ecosolidaria_empreendimento.asp>. Acesso em $19 \mathrm{de}$ out. 2012.

MCINTYRE, J. P.; BERGONSI, S. M.; CHAKDA, Y.; FORTIN, M. E. Modelo de intercooperação de incubação de cooperativa. In: ENCONTRO DE INVESTIGADORES LATINO AMERICANOS DE COOPERATIVISMO DEL ACI, III, 2004. Anais... Porto Alegre: ACI, 2004. CD-ROM.

OCDE. Organização para Cooperação e Desenvolvimento Econômico. Manual de Oslo: diretrizes para coleta e interpretação de dados sobre inovação. 3. ed. Brasília: FINEP, 2005.

OLIVEIRA, L. V. N. Economia solidária e conjuntura neoliberal: desafios para as políticas públicas no Brasil. Curitiba. Dissertação (Mestrado em Direito). Universidade Federal do Paraná. 2005.

PETITCLERC, M. Rapport sur les innovations socials et les transformations socials. Collection études théoriques, n. ET0314, nov. 2003.

PIRES, M. L. L. S.; SILVA, E. S.; SALOMÃO, I. L.; INTYRE, J. P.; GUERREIRO, J.; ALBUQUERQUE, P. P.; BERGONSI, S. S. S.; VAZ, S. C. Cenários e tendências: do cooperativismo brasileiro. Recife: Bagaço, 2004. 


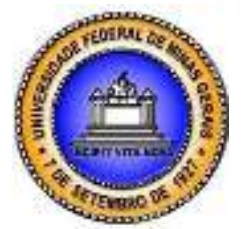

RICHARDSON, R. J. Pesquisa social: métodos e técnicas. São Paulo: Atlas, 1999.

RIEIRO, A.; DABEZIES, M. J. Vulnerabilidad y políticas de inclusión: ¿son las cooperativas sociales un camino hacia mayores grados de autonomía? In: CONGRESSO DA REDE DE ITCPS, II, 2009. Anais... São Paulo: Rede de ITCPs, 2009 CD-ROM.

ROGERS, E.; SHOEMAKER, F. F. Communication of innovations: a cross cultural approach. New York: Free Press, 1971.

ROTHWELL, R.; ZEGVELD, W. Innovation and the small and medium sized firm. London: Frances Printer, 1982.

RTS. Rede de Tecnologia Social. Descrição da tecnologia social: incubação e apoio a empreendimentos $2005 . \quad$ solidários. $<$ http://www.rts.org.br/bibliotecarts/relatorios-

1/ts_descricao_incubacao_apoio_empreendimentos_solidarios.pdf $>$. Acesso em $20 \mathrm{de}$ fev. 2012.

SANTANA, A. C. Incubadoras tecnológicas de cooperativas populares e economia solidária: as transformações no "mundo" do trabalho. In: SEMINÁRIOS EM ADMINISTRAÇÃO, XI, 2008. Anais... São Paulo: SEMEAD, 2008. CD-ROM.

SCHUMPETER, Joseph. The theory of economic development. Harvad University Press, 1939.

SEBRAE. Serviço de Apoio às Micro e Pequenas Empresas. Fatores condicionantes e taxas de sobrevivência e mortalidade das micro e pequenas empresas no Brasil: 2003-2006. Brasília, DF, 2007. Disponível em: <http://www.sebrae.com.br>. Acesso em 11 de mar. 2012.

SINGER, P. Introdução à economia solidária. São Paulo: Editora Fundação Perseu Abramo, 2002 .

TARDIF, C. Complémentarité, convergence et transversalité: la conceptualisation de l'innovation sociale au Crises. Collection études théoriques, n. ET0513, dec. 2005.

TYSZLER, M. Mudança social: uma arte? Empreendimentos sociais que utilizam a arte como forma de mudança. Revista de Administração Pública, Rio de Janeiro, v. 41, n. 6, p. 1017-1034, nov./dez. 2007.

YIN, R. K. Estudo de caso: planejamento e métodos. Porto Alegre: Bookman, 2005.

ZAWISLAK, P. A. Gestão da Inovação Tecnológica e Competitividade Industrial: Uma Proposta para o Caso Brasileiro. In: ENCONTRO NACIONAL DA ANPAD, XIX, 1995, João Pessoa. Anais...João Pessoa: ANPAD, 1996. CD-ROM. 